\title{
Entscheidungshilfe
}

\section{Allergie-Patienten und COVID-19-Impfung}

Was bei positiver Allergieanamnese vor einer Impfung gegen COVID-19 zu beachten ist.

Das Paul-Ehrlich-Institut PEI betont in seinem Bulletin (1/2021): „Für alle bisher eingesetzten COVID-19-Impfstoffe in Deutschland - Comirnaty ${ }^{\circledast}$, COVID-19 Vaccine Moderna ${ }^{\circledR}$ und Vaxzevria ${ }^{\circledR}$ - wurden in sehr seltenen Fällen schwere anaphylaktische Reaktionen nach Impfung (99 Fälle auf 8,9 Millionen Impfungen, Stand: 12.03.2021) berichtet."

Das PEl hat gemeinsam mit dem RKI und deutschen allergologischen Fachgesellschaften ein Flussdiagramm entwickelt, das wie folgt kategorisiert:

Mit einer COVID-19-mRNA-Vakzine geimpft werden können (bei Nachbeobachtungszeit von 15 Minuten) Patienten mit:

- Kontrolliertem Asthma bronchiale,

- Rhinoconjuntivitis allergica inklusive Heuschnupfen, Milbenallergie,

- Neurodermitis,

- Nahrungsmittelallergie,

- Bienen-/Wespengiftallergie,

- Medikamentenallergie (nicht PEGassoziiert),
- Kontaktallergie (etwa Duftstoffe, Nickel).

Geimpft werden können außerdem (unter erhöhter Notfallbereitschaft und bei Nachbeobachtungszeit von 30 Minuten) Patienten mit:

- Anaphylaxie/schwerer allergischer Reaktion auf Medikamente oder einen anderen Impfstoff/ Impfstoffbestandteil, der nicht in COVID-19-Impfstoffen enthalten ist,

- Generalisierter Urtikaria (oder andere monosymptomatische Allergiemanifestationen) nach COVID-19-mRNA-Impfung,

- Mastozytose.

Besondere Vorsicht bei Patienten mit:

- Anaphylaxie/schwere allergische Reaktion nach 1. oder 2. Dosis eines COVID-19-mRNA-Impfstoffs,

- Ärztlich behandelter Anaphylaxie/schwerer allergischer Reaktion $>1 \mathrm{~h}$ (bis $24 \mathrm{~h}$ ) nach COVID-19-mRNA-Impfung,
- Bekannte Überempfindlichkeit auf einen Inhaltsstoff in den COVID-19-mRNA-Impfstoffen,

- Bekannte allergische Reaktionen auf PEG oder PEG-haltige Arzneimittel (Laxanzien, Darmspüllösungen vor Endoskopie),

- Anaphylaxie/schwere allergische Reaktion unklarer Ursache.

Diese Patienten sollten sich persönlich in einem allergologischen Zentrum vorstellen, bei ihnen sollte eine lgE-vermittelte allergische Genese geprüft werden .

Das Flussdiagramm zum Download: https://bit.ly/3mNxfGF

Hinweis des Verlags. Der Verlag bleibt in Hinblick auf geografische Zuordnungen und Gebietsbezeichnungen in veröffentlichten Karten und Institutsadressen neutral.

hautnah $2021 \cdot 20: 81$

https://doi.org/10.1007/s12326-021-

00445-7

(C) Springer-Verlag GmbH Austria, ein Teil von Springer Nature 2021
Quelle: Anne Bäurle/ Ärzte Zeitung, SpringerMedizin.at

Hier steht eine Anzeige. 